\title{
SIMS investigation of electron-beam damage to hydrous, rhyolitic glasses: Implications for melt inclusion analysis
}

\author{
MADEleine C.S. Humphreys,* StuART L. Kearns, AND Jon D. BLundy
}

Department of Earth Sciences, University of Bristol, Wills Memorial Building, Queen's Road, Bristol, BS8 1RJ, U.K.

\begin{abstract}
Electron-beam irradiation causes permanent damage to hydrous, silica-rich glasses. The extent of electron-beam damage is quantified using data generated by SIMS analysis of points subjected to previous electron microprobe analysis (EPMA). Even optimum EPMA conditions cause damage to the glass, manifest as a marked depletion in alkali ions at the surface of an irradiated sample. Deeper in the sample, an enrichment in alkali ions to above-baseline levels is followed by a decay back to baseline. The depth of the final decay correlates with species diffusivity and increases in the order $\mathrm{K}$-Li-Na. H-bearing species are also affected by electron beam irradiation, but in the opposite sense to the alkalis, i.e., they are enriched at the surface. Migration of alkaline earth cations is not observed because of their low diffusivities. Ion depletion or enrichment results from simple migration of ions toward or away from electrons implanted by the beam. Migration depth depends on species diffusivity and heating caused by the electron beam, and therefore increases with increasing electron beam current. Because of the reverse behavior of $\mathrm{H}$, the mobile hydrous species in the presence of an electric field is probably $\mathrm{OH}^{-}$. The extent of electron beam damage to glasses may increase with total water content. Critically, SIMS measurements of $\mathrm{H}, \mathrm{Li}, \mathrm{Na}, \mathrm{D} / \mathrm{H}$, and ${ }^{6} \mathrm{Li} /{ }^{7} \mathrm{Li}$ after electron-probe analysis are compromised by the damage. Despite the damage caused by the electron beam, use of appropriate electron-beam conditions (e.g., $2 \mathrm{nA}, 15 \mathrm{kV}$ ) gives volatiles by difference accurate to $0.6 \mathrm{wt} \%$.

Keywords: Electron-probe microanalysis, rhyolite glass, melt inclusions, secondary ion mass spectrometry, diffusion
\end{abstract}

